\title{
Brachytherapy in the treatment of bile duct cancer - a tough challenge
}

\author{
Prof. Janusz Skowronek, MD, PhD1,2, Grzegorz Zwierzchowski, MSc, PhD2,3 \\ 'Brachytherapy Department, Greater Poland Cancer Center, Poznan, 'Electroradiology Department, Poznan University of Medical Sciences, Poznan, \\ ${ }^{3}$ Medical Physics Department, Greater Poland Cancer Center, Poznan, Poland
}

\begin{abstract}
The majority of patients with bile duct cancer are diagnosed with clinically advanced disease. Most of these patients have a short life expectancy and are treated with palliative aim. Most patients present with locally advanced or metastatic disease, which is not amenable to surgical resection, resulting in poor survival. Adjuvant or definitive radiotherapy, with or without chemotherapy, is therefore used in many centers worldwide for better local control, and with the expectation that it will have a favorable effect on survival. However, the lack of appropriate prospective trials, as well as the small size of the published series and their retrospective nature, has produced insufficient evidence for the best treatment for these patients. Intraluminal brachytherapy is an important component in the multimodality approach to bile duct cancers. The objective of this treatment is to deliver a high local dose of radiation to the tumor while sparing surrounding healthy tissues. The treatment can be safely adapted for right and left hepatic duct, and for common bile duct lesions. Brachytherapy plays a limited but specific role in definitive treatment with curative intent in selected cases of early disease, as well as in the postoperative treatment of small residual disease. Depending on the location of the lesion, in some cases, brachytherapy is a treatment of choice. Clinical indications, different techniques, results, and complications are discussed in this work.

Key words: bile duct cancer, brachytherapy, endoluminal, palliation, prosthesis.

\section{Purpose}

Biliary tract cancer is a rare disease. Surgical resection offers the best chance for long-term survival, but the results are not satisfactory and local relapses are frequent $[1,2]$. Bile duct cancer is a rare tumor in developed countries; there are diagnosed approximately 10,000 new cases per year in United States. In 2015, in USA, there were 10,910 estimated new gallbladder and other biliary cancer cases (men - 4,990; women - 5,920), and 3,700 prognosed deaths: men -1,660; women - 2,040 [3]. The 5-year overall survival (OS) rate is estimated at 5-30\%. In Japan, 20,734 new cases were diagnosed in 2007 [1]. In Poland (2011), there were diagnosed 1207 gallbladder cancers and 627 bile ducts and carcinoma of the ampulla of Vater, respectively. Biliary tract tumors have a higher incidence in Asia, particularly in Thailand, Korea, India, and Japan. It is one of the most common cancers in endemic areas of developing countries, as high as 87 per 100,000 people in northeast Thailand. The major risk factor in Western countries is primary sclerosing cholangitis, which is closely associated with chronic inflammatory bowel disease, particularly ulcerative colitis. The risk of developing cholangiocarcinoma is higher in patients with primary sclerosing cholangitis, ulcerative colitis, and colonic neoplasm, than in patients with primary sclerosing cholangitis and ulcerative colitis without colonic neoplasm. In Japan, patients with hepatitis $\mathrm{C}$ virus (HCV) infection have 1,000 times higher incidence than would be expected in the general population, and the accumulated rate of newly diagnosed cholangiocarcinoma is $1.6 \%$ at 5 years and $3.5 \%$ at 10 years. In Asia, chronic infections of the biliary tract and infestation by certain liver flukes, such as Clonorchis sinensis and Opisthorchis viverinni are associated with cholangiocarcinoma and hepatolithiasis. Hepatolithiasis itself is also a risk factor for cholangiocarcinoma; $5 \%$ to $10 \%$ of patients with intrahepatic stones develop this complication [4]. The majority of bile duct carcinomas involve the hepatic duct bifurcation, the common hepatic duct, the cystic duct, and the ampulla. Tumor can spread along the sinusoids and neoplastic destruction of normal cholangioles leads to the retention of bile around the margin of the tumor. Tumor emboli in the portal and hepatic veins are common and vascular invasion can occur in up to $90 \%$ of cases. Local relapses are frequent. The tumor may also metastasize to lungs, peritoneum, and intra-peritoneal organs. Patients commonly present with obstructive jaundice. 


\section{General treatment rules}

Treatment options for bile duct cancer remain limited due to the large number of patients with advanced disease at the time of diagnosis $[5,6,7,8,9,10]$. Unresectable bile duct cancers are very difficult to treat with external beam radiotherapy (EBRT) alone due to the proximity of adjacent normal organs and the high doses required to effectively irradiating these neoplasms $[2,11,12,13]$. The only curative treatment seems to be a radical surgical excision. However, because of the propensity of cholangiocarcinomas to invade the hepatic artery, portal vein, and other vital structures this is only feasible in 10 to $15 \%$ of cases, and is associated with an operative mortality of 5 to $10 \%[6,14,15,16]$.

Patients with inoperable peri-hilar cholangiocarcinoma usually have obstructive jaundice and should be treated with endoscopic or percutaneous drainage and/ or stent placement initially. External beam therapy alone rarely controls advanced disease. Combinations of EBRT, different schedules of chemotherapy, and intraluminal brachytherapy (ILBT) may relieve pain and contribute to biliary decompression, and sometimes achieve long-term survival [17]. Investigators have had the broadest experience with fluorouracil (5-FU), which has response rates of approximately $14 \%$. Single-agent activity has been noted with other drugs, such as adriamycin, but clinical results have been disappointing. Currently, no combination regimen has been proven sufficiently to become an established therapy. In some cases, combined chemotherapy and radiotherapy may delay the progression of cholangiocarcinomas, and to provide the chance for liver transplant $[18,19,20]$.

Usually, a 1-2 weeks' interval is planned between the completion of EBRT and brachytherapy (BT). Patients should be fit enough (WHO score 0-2) for the procedure, and should have been reviewed to confirm that they are not suitable for resection. Combined treatment is possible in patients who are in reasonably good condition; it is usual to combine BT with EBRT [9,21,22,23,24,25,26,27,28]. Although the results available in the literature are somewhat contradictory with regard to the possible use of BT in a curative setting, some evidence indicates that BT can improve results of the treatment of unresectable extrahepatic bile duct and pancreatic cancers, if a proper subset of patients is identified, and a rational and aggressive scheme of multimodality treatment is designed $[29,30,31]$.

Until now, no prospective controlled trial including significant patient cohorts with enough statistical power has been conducted to determine the impact of BT on survival outcomes [32].

\section{Clinical indications}

\section{Radical treatment}

Indications for BT can be summarized as follow: 1) BT as a radical treatment: alone in small inoperable tumors, or in combination with EBRT and/or chemotherapy in advanced disease for unresectable patients; 2) BT as an adjuvant treatment after non-radical excision, possibly combined with EBRT.

\section{Palliative treatment}

Brachytherapy as a palliative treatment is often performed in order to facilitate the outflow of bile (irrespective of the size of the tumor, including large inoperable tumors with significant extraductal disease). For unresectable patients, the goal of treatment is prevention of locoregional disease progression to enhance quality of life and survival. In almost all cases, such palliative treatment is recommended for Klatskin tumors. This group of indications occurs most frequently.

\section{Contraindications}

Most frequently are mention: 1 ) significant risk of radiation-induced severe complications in organs at risk (OARs); 2 ) poor general condition (WHO score $>2$ ) $[2,4,11,22]$. Decision should be made individually for every patient.

\section{Brachytherapy techniques}

Typically, brachytherapy is delivered through a percutaneous transhepatic biliary drainage (PTBD) tube (percutaneous trans-hepatic cholangiograpgy - PTC) placed under fluoroscopic guidance or through catheters placed in the tumor bed during surgery. The trans-duodenal endoscopic technique is used less frequently.

\section{Trans-hepatic technique}

Wherever possible, it is best to use a percutaneous trans-hepatic technique, which allows for the passage of a catheter through the stricture. Cholangiography is performed and then radiographs with a dummy source in the catheter. The transhepatic catheter placement (during percutaneous transluminal coronary angioplasty - PTCA) has the advantage of providing both internal drainage across the tumor and external drainage via the proximal end of the catheter. In the face of a refractory obstruction, BT to the proximal tumor may further help to open up the channel to the duodenum. This is nowadays the preferred approach in most cases [2,4,9,33]. Both, HDR (high-doserate) and PDR (pulsed-dose-rate) BT are well tolerated and can be applied.

The technique includes the following steps: 1) identifying the site and length of the malignant stricture by cholangiogram; 2) biliary drainage with minimum 10 French diameter catheter (usually done by the interventional radiologist); 3) inserting a BT blind-ended catheter (usually 5 or 6 French) through the biliary drainage 10 French catheter; 4 ) a marker wire is then passed into the brachytherapy catheter, and orthogonal radiographs are obtained for computerized 2D dosimetry (or computed tomography [CT] scans in case of 3D planning); 5) treatment planning procedure.

\section{Trans-duodenal endoscopic technique [34]}

Trans-duodenal endoscopic approach is less frequently used technique. Before the procedure, endoscopic retrograde cholangiography (ERC) is performed to identify the site of the tumor, the length of bile duct involved, 
and the extent of disease. Endoscopic retrograde cholangiopancreatography (ERCP) is first performed and a sphincterotomy carried out to allow cannulation of the bile duct. A guide wire is then advanced through the malignant stricture and beyond. The endoscope is removed, and then a naso-biliary tube threaded over the guide wire beyond the stricture into the biliary tree. The procedure is done under fluoroscopy to check the position of the guide wire and the naso-biliary tube. The tube is finally taped to the patient's nose.

An afterloading catheter containing a radio-opaque marker wire is then passed through the naso-biliary tube under fluoroscopy and advanced through the lesion. The radio-opaque wire has markers at intervals, which indicate where the radioactive source should be placed. Orthogonal radiographs are taken to confirm the position and to perform the dose calculation (or 3D on CT).

Loading the radioactive source into the catheter is similar to that described for the percutaneous trans-hepatic technique.

The naso-biliary catheter can be attached to a remote afterloading machine, which will give a fraction of HDRBT (PDR-BT is not recommended because of the short tolerance of endoscopy). In this case, the dwell positions of the source must be programmed considering the measured distances from the localizing radiographs.

\section{Target volume and planning}

\section{D planning}

The location and length of the stenotic bile duct tumor should be identified at PTC and/or ERCP or magnetic resonance cholangiopancreatography (MRCP). In case of 2D planning for the clinical target length (CTL), a $1 \mathrm{~cm}$ margin is taken proximally and distally of the visible stenosis. Using PTC or ERCP alone, no individual tumor and target depth can be defined, as extraductal disease can only be defined by additional sectional imaging (CT/MRI).

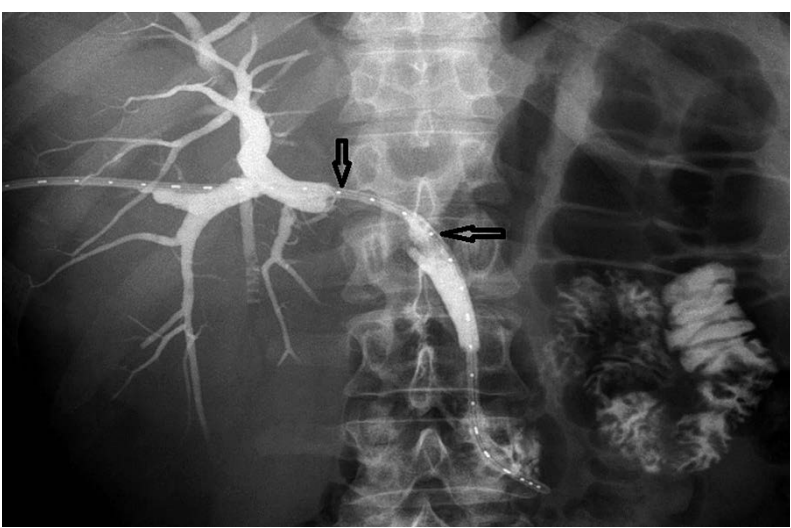

Fig. 1. Trans-hepatic approach based on a percutaneous transhepatic cholangiogram. Bile duct cancer, dilated common hepatic, and right and left hepatic ducts with interruption of contrast filling (arrows) after cholangiography. 5 French brachytherapy catheters with radio-opaque marker wire introduced via the right hepatic duct passing through the stenosis and reaching the duodenum via the common bile duct
In most of the cases, 2D planning is still the method of choice - due to the palliative aim of the treatment and the poor condition of the majority of patients. Presence of jaundice may also be a reason to shorten the planning process. X-ray images are taken directly during PTC. Clinical target length is defined as a $1 \mathrm{~cm}$ margin taken proximally and distally from the visible stenosis, which indicates the length of the gross tumor volume (GTV) (Figure 1 and 2). Dose specification for prescription is done at $1 \mathrm{~cm}$ from the source axis [2,9].

\section{D planning}

In case of 3D planning, the GTV is defined as any visible tumor by CT and/or MRI. Clinical target volume (CTV) may be e.g., defined as $1-1.5 \mathrm{~cm}$ margin to the GTV, especially along the bile duct and to the target depth, which needs to be determined (it could also include an adjacent lymph node). A planning target volume may be defined by adding a margin of 0.5 to $1 \mathrm{~cm}$ to the CTV. When using CT for 3D treatment planning, 1 to $3 \mathrm{~mm}$ slice thickness is recommended, and contrast medium to reconstruct the bile ducts and to visualize the GTV. The GTV is defined as any tumor visible through CT and/ or MRI. Clinical target volume is defined as 1 to $1.5 \mathrm{~cm}$ distance from the GTV (in depth), especially along the bile duct and potential lymphatic drainage areas, which include nodes along the porta hepatis, pancreaticoduode-

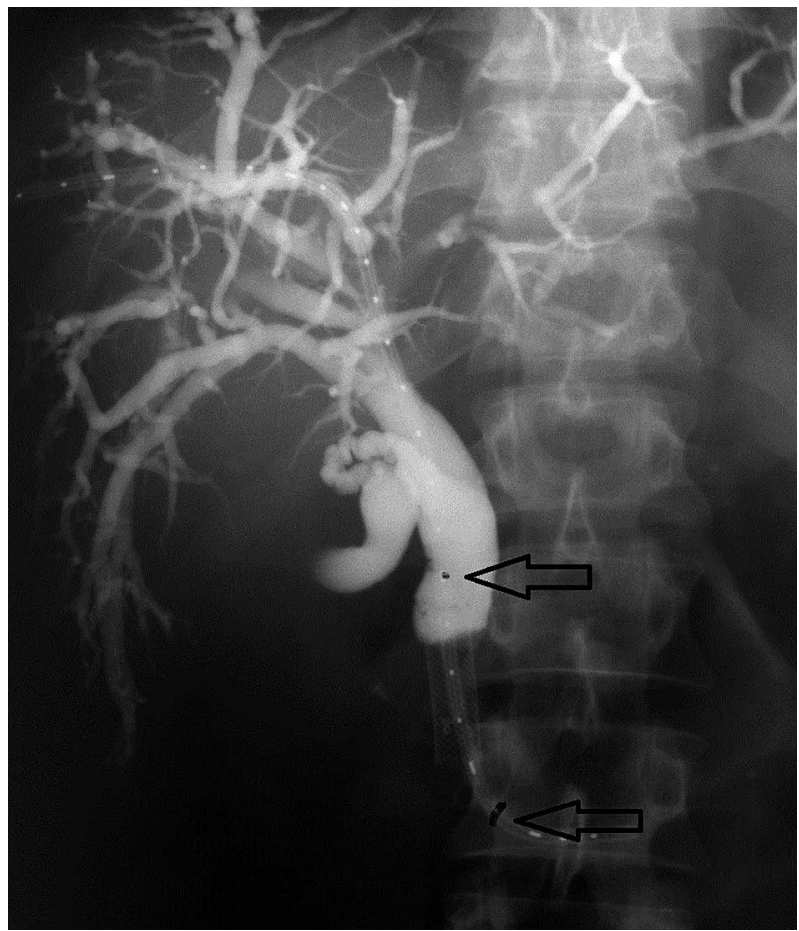

Fig. 2. Trans-hepatic approach based on a percutaneous trans-hepatic cholangiogram. Bile duct cancer with recurrence after insertion of stent, bile ducts visible after cholangiography, obturated part visible as a break, 5 French brachytherapy catheters with radio-opaque marker inside, irradiated length (arrows) has $5 \mathrm{~cm}$ ( $3 \mathrm{~cm}$ of obturated bile duct and a margin of $1 \mathrm{~cm}$ distally and proximally) 
nal system, and celiac axis $[35,36]$. Treating nodal disease with brachytherapy is usually not possible. The planning target volume (PTV) is defined by adding in the longitudinal direction a margin of $1 \mathrm{~cm}$ both, distally and proximally to the CTV [20]. The dose-limiting surrounding organs (both for EBRT and BT) include the liver, pancreas, duodenum, small bowel, stomach, and spinal cord.

Planning procedures for PDR or HDR treatment schedules are performed using 3D planning systems, e.g., in Poznan - Oncentra Brachy (Nucletron, an Elekta company, Elekta $A B$, Stockholm, Sweden) treatment planning system. For the reconstruction of the application, a geometry set of CT scans with $2.5 \mathrm{~mm}$ layer width is prepared. Radiopaque marker is inserted inside catheter for assuring precise visibility, and manual tracking is performed.
Contrast placed in the bile ducts enables precise location of the stenosis. Liver, pancreas, stomach, and duodenum are delineated and used as critical structures for dose planning and optimization procedure. Clinical target volume is delineated as the rounded volume around the reconstructed catheter (Figure 3 ).

For the PDR treatment, the dose of 0.8 Gy per pulse is prescribed to the dose points placed on the surface of the CTV (Figure 4). Finally, the source steep of $2.5 \mathrm{~mm}$ and active length of $50 \mathrm{~mm}$ with 21 active positions is used for treatment delivery. Reference dose is prescribed and normalized to the dose points and manually optimized using graphical method.

Basic dose statistic values as the result of optimization are presented in the Table 1. Treatment plan analysis and
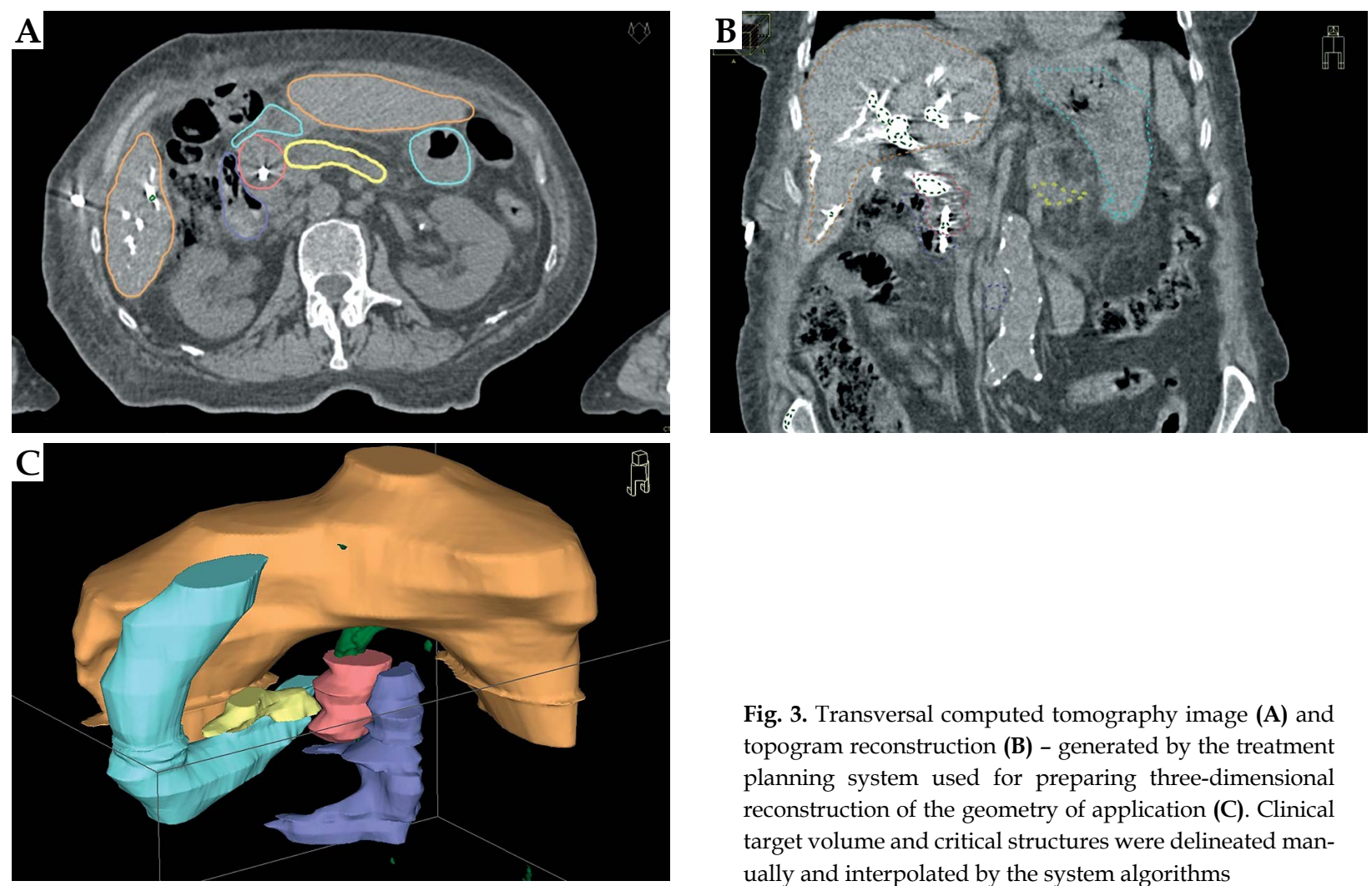

Fig. 3. Transversal computed tomography image (A) and topogram reconstruction (B) - generated by the treatment planning system used for preparing three-dimensional reconstruction of the geometry of application (C). Clinical target volume and critical structures were delineated manually and interpolated by the system algorithms
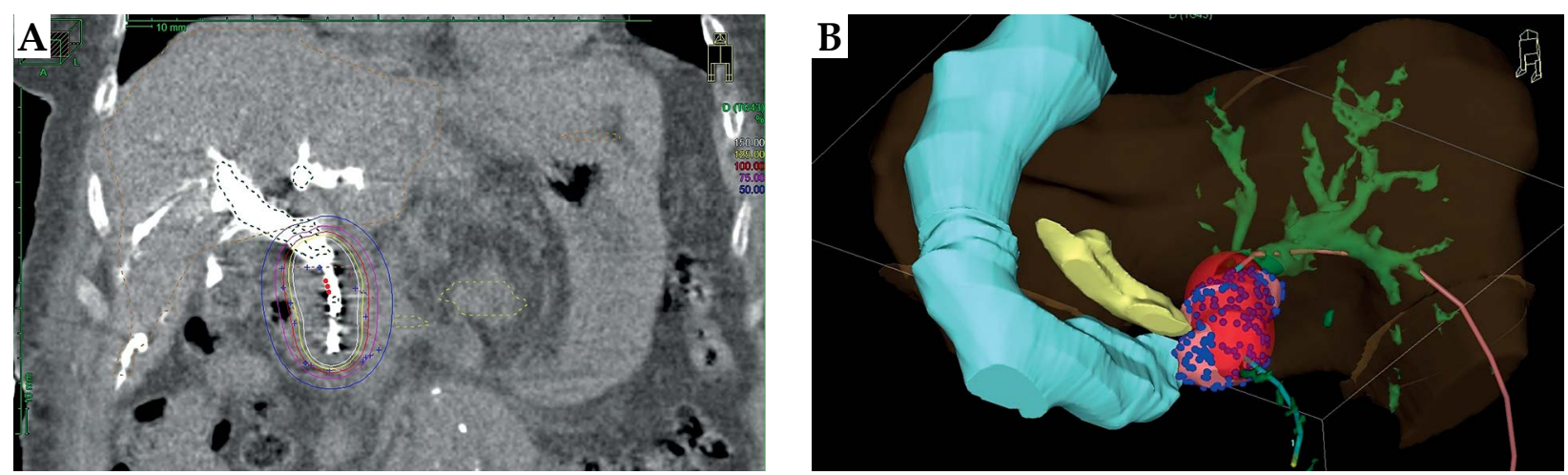

Fig. 4. 2D (A) and 3D (B) reconstruction of the geometry of application with catheter, clinical target volume (CTV), 100\% isodose and critical structures. Blue points located on the CTV surface represents dose reference points used for the dose prescription 
Table 1. Dose statistics and volume information. Calculation for the optimized dose distribution, histogram values for treated volume (clinical target volume, CTV), and organs at risk volumes (duodenum, stomach, liver, and pancreas). The dose value of $800 \%$ is the maximum value calculated by the planning system algorithm

\begin{tabular}{lcccccc} 
Structure & Min dose [\%] & Max dose [\%] & Median dose [\%] & Average dose [\%] & Std. dev. [\%] & Volume [ccm] \\
\hline Contrast & 3.3 & 800.00 & 15.3 & 66.8 & 126.9 & 17.3 \\
\hline External & 1.7 & 800.00 & 7.4 & 13.4 & 30.1 & 3175.5 \\
\hline CTV & 44.7 & 800.00 & 160.5 & 220.6 & 168.8 & 27.5 \\
\hline Duodenum & 5.9 & 687.88 & 26.1 & 34.2 & 28.9 & 54.3 \\
\hline Stomach & 3.5 & 69.11 & 12.5 & 15.0 & 8.6 & 35.8 \\
\hline Liver & 1.8 & 86.96 & 7.1 & 8.9 & 6.3 & 794.3 \\
\hline Pancreas & 8.2 & 98.00 & 17.0 & 23.3 & 15.9 & 8.7
\end{tabular}

optimization procedure are based on dose distribution parameters calculated from cumulative dose volume histogram (Figure 5). Dose volume histogram (DVH) markers for CTV, duodenum, stomach, pancreas, and liver doses are analyzed. Dose distribution parameters for CTV and critical, respectively, are presented in Table 2 and Table 3.

\section{Treatment schedules $[2,4,5,9,22]$}

In patients who are in reasonably good condition, it is usual to combine bile duct BT with EBRT. Typically,
30 to 40 Gy (2 Gy fractions) are delivered through EBRT to a volume, which encompasses the porta hepatis, the common bile duct and regional nodes. For BT, the dose commonly used is 15-20 Gy prescribed to the BT related PTV, generally over 2-3 treatments (HDR-BT).

In the same group of patients, radical PDR-BT may be proposed with curative intent. Brachytherapy can be used after EBRT (40 Gy) in 1 course of 20 Gy (pulses of 0.5-0.8 Gy every hour). For monotherapy, when EBRT is not recommended, 2-3 courses of 20 Gy (pulses of 0.5-0.8 Gy every hour) are proposed [7]. After non-radical resection, 40-50 Gy

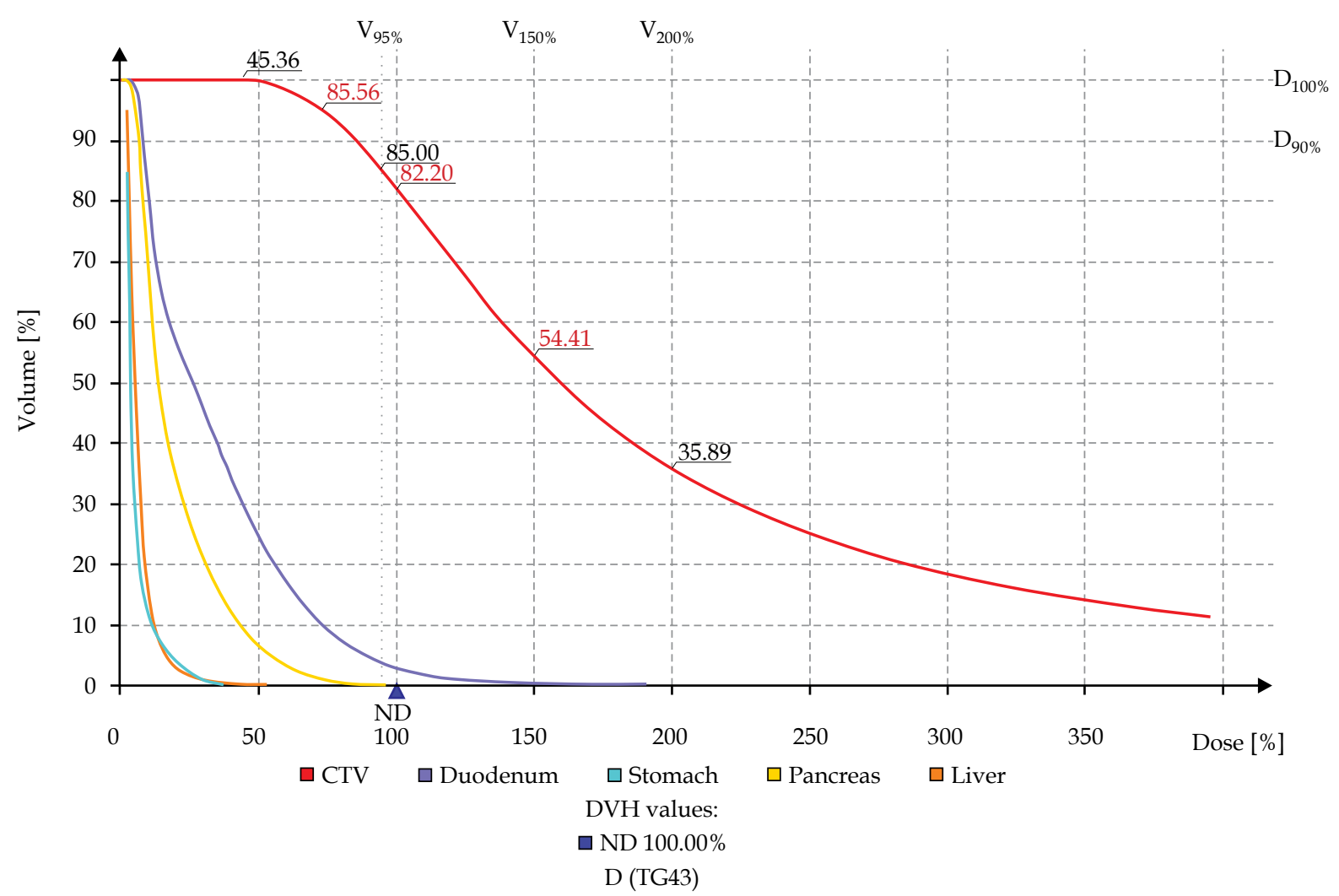

Fig. 5. Cumulative dose volume histogram for analyzed case with used DVH markers for CTV, duodenum, stomach, pancreas, and liver doses 
Table 2. Dose volume histogram (DVH) markers for critical structures. Physical parameters of the dose distribution calculated using dose volume histogram data for the critical structures, percentage doses for the clinically relevant volumes of the structures $(0.1 \mathrm{ccm}, 1.0 \mathrm{ccm}$, and $2 \mathrm{ccm}$, respectively)

\begin{tabular}{lccc}
$\begin{array}{l}\text { Structure/ } \\
\text { DVH marker }\end{array}$ & $\mathrm{D}_{0.1 \mathrm{ccm}}[\%]$ & $\mathrm{D}_{1 \mathrm{ccm}}[\%]$ & $\mathrm{D}_{2 \mathrm{ccm}}[\%]$ \\
\hline Liver & 74.2 & 57.5 & 50.3 \\
\hline Pancreas & 74.9 & 44.9 & 32.8 \\
\hline Stomach & 57.1 & 35.9 & 30.7 \\
\hline Duodenum & 173.5 & 108.8 & 95.1
\end{tabular}

in 2-3 courses (PDR-BT) can be applied (see 3D planning rules).

For palliative treatment, $20-40$ Gy in one or two courses are suggested. Pulsed-dose-rate BT is recommended for the trans-hepatic technique [2,9] at $10 \mathrm{~mm}$ from the source axis using 2D. When using HDR-BT for palliative patients, the dose commonly used is 15-20 Gy (3-4 Gy fractions, 4-5 Gy/fraction) prescribed, generally over 2-3 applications at $10 \mathrm{~mm}$ depth.

\section{Side effects}

Intraluminal brachytherapy does increase the risk of cholangitis and bleeding due to inserting catheters into the biliary tract, as late complications bile duct stenosis or stricture are observed. The exact rate is unknown due to different cohorts of patients and treatment methods analyzed in published papers.

Acute complications of RT and ILBT include nausea, vomiting, and transient elevation of transaminase. These effects are usually mild and tolerable [4].

Late complications are associated with radiation dose (EBRT related) to surrounding organs. The most common complications are gastrointestinal bleeding, biliary bleeding, and duodenal stenosis. With external-beam doses of $<55$ Gy to the duodenum or stomach, the risk of severe gastrointestinal complications varies from $5 \%$ to $10 \%$. At doses $>55 \mathrm{~Gy}$, one-third of patients develop severe problems [3].

\section{Results}

For patients with unresectable disease, many researchers have favored EBRT with or without BT to prolong survival. In the Table 4, analyzed groups are heterogeneous and small but there is a tendency in these results. Most frequently OS ranges from 10 to 15 months.

In a recently published study by Yoshioka et al. [32], the results on the impact of BT on OS, disease-specific survival (DSS), and local control (LC) were reported. The group comprised 209 patients, including 153 who underwent EBRT alone, and 56 who received both BT and EBRT. It was concluded that in the treatment for unresectable biliary tract cancer, the addition of BT to EBRT has no impact on OS or DSS, but is associated with better
Table 3. Dose volume histogram (DVH) markers for critical structures. Physical parameters of the dose distribution calculated using DVH data for the clinical target volume (CTV). $\mathrm{V}_{100}, \mathrm{~V}_{150}, \mathrm{~V}_{150}$ - percentage volume of the CTV covered by $100 \%, 150 \%$, and $200 \%$ isodose, respectively, $D_{90}, D_{100}$ - percentage dose delivered to $90 \%$ and $100 \%$ of the CTV

\begin{tabular}{lcc} 
& Dose [\%] & Volume [\%] \\
\hline$V_{100}$ & 100 & 82.2 \\
\hline$V_{150}$ & 150 & 54.4 \\
\hline$V_{150}$ & 200 & 35.8 \\
\hline$D_{90}$ & 85.5 & 90 \\
\hline$D_{100}$ & 45.3 & 100
\end{tabular}

LC: the 2-year LC rates were $65 \%$ for the ILBT (+) group and $35 \%$ for the ILBT (-) group. Therefore, the role of BT should be addressed by other measures than survival benefit, for example by benefit in toxicity, prolonged biliary tract patency decreasing the need for further palliative interventions, or benefit in quality of life.

Shinohara et al. [29] noted a survival benefit of BT in comparison between BT and no radiotherapy (RT) groups. Their study cohort included not only unresectable but also postoperative patients (median survival for patients treated with brachytherapy was 11 months; $95 \%$ confidence interval [CI] 9-13 months), compared with 4 months for patients who received no radiation $(p<0.0001)$.

Chen et al. [31] evaluated the clinical effect on stent patency and patient survival of 34 patients with obstructive jaundice (14 treated with BT, 20 [group A] - control group [B]). High-dose-rate was used with fractional doses of 4-7 Gy given every 3-6 days for 3-4 times. Mean stent patency of group A (12.6 months) was significantly longer than that of group B ( 8.3 months) $(p<0.05)$. There was a considerable difference in the mean survival (9.4 months vs. 6.0 months) between the two groups (not significant).

There are very few reports on BT monotherapy. Skowronek et al. published in 2009 [9] results of 29 patients with bile duct cancer treated palliatively exclusively with PDR-BT. In most cases, 20 Gy using PDR-BT was given (pulse 0.8 Gy every hour/1 cm). In 19/29 (65.5\%) of bile duct cancer cases, clinical improvement (decrease of jaundice) was noted after 4 weeks. Median OS for bile ducts cancer patients was 11.2 months.

\section{Conclusions}

Intraluminal brachytherapy may be an important component in the multimodality approach of bile duct cancers. The objective of this treatment is to deliver a high local dose of radiation to the tumor while sparing surrounding normal tissues. The treatment can be safely adapted for right and left hepatic duct as well as for common bile duct lesions.

1. Brachytherapy has a potential benefit because it may enhance local control and prolong patency of the bili- 
Table 4. Published selected results of combined external beam radiotherapy and brachytherapy

\begin{tabular}{|c|c|c|c|c|c|c|}
\hline Author & $\begin{array}{l}\text { Number of } \\
\text { patients }\end{array}$ & EBRT, dose & $\begin{array}{l}\text { BT, number } \\
\text { of fractions, } \\
\text { fraction dose, } \\
\text { method }\end{array}$ & $\begin{array}{l}\text { Prescription } \\
\text { depth }\end{array}$ & $\begin{array}{l}\text { Results } \\
\text { of treatment }\end{array}$ & $\begin{array}{l}\text { Statistical } \\
\text { analysis }\end{array}$ \\
\hline Foo et al. [21] & 24 & $\begin{array}{l}\text { Median: } 50.4 \text { Gy, } \\
1.8 \text { Gy/fraction }\end{array}$ & $\begin{array}{c}192 \text { Ir seeds, } \\
20 \text { Gy (median) }\end{array}$ & $\begin{array}{l}\mathrm{BT}-20 / 24 \text { dose } \\
\text { prescribed at } \\
10 \mathrm{~mm} \text {, } \\
2 / 24-5 \mathrm{~mm} \text {, } \\
7.5 \text { and } 7.0 \mathrm{~mm} \text { in } \\
1 / 24 \text { patient }\end{array}$ & $\begin{array}{l}\text { MS: } 12,0 \text { months } \\
2 \text { yrs: } 18,8 \text { months } \\
5 \text { yrs: } 14,1 \text { months }\end{array}$ & $p=0.39$ \\
\hline Fritz et al. [28] & 30 & $\begin{array}{l}30-45 \text { Gy in } \\
25 \text { patients }\end{array}$ & $\begin{array}{l}\text { HDR, 5-10 Gy } \\
\text { fractions, total } \\
\text { dose } 20-45 \text { Gy }\end{array}$ & $\begin{array}{l}\text { Dose prescribed } \\
\text { at } 10 \mathrm{~mm}\end{array}$ & $\begin{array}{c}\text { MS: } 10 \text { months } \\
2 \text { yrs: } 18 \% \\
5 \text { yrs: } 8 \%\end{array}$ & n.d. \\
\hline $\begin{array}{l}\text { Yoshioka et al. } \\
\text { [32] }\end{array}$ & $\begin{array}{l}1.153 \\
2.56\end{array}$ & $\begin{array}{l}\text { Median: } 50 \mathrm{~Gy}, \\
\text { fractions } 1.8 \text { or } \\
2.0 \mathrm{~Gy}\end{array}$ & $\begin{array}{l}\text { 1. No } \\
\text { 2. } 18 \text { Gy median } \\
(3 \times 6 \text { Gy frac- } \\
\text { tions }) \text { HDR }\end{array}$ & $\begin{array}{c}\text { 2. 43/56 cases - } \\
\text { dose prescribed } \\
\text { at } 10 \mathrm{~mm} \text {, } \\
\text { 4/56 - at } 12 \mathrm{~mm} \text {, } \\
5 / 56 \text { - at } 5 \mathrm{~mm}\end{array}$ & $\begin{array}{l}\text { 1. OS ( } 2 \text { yrs): } 40 \% \\
\text { DSS ( } 2 \text { yrs): } 41 \% \\
\text { LC ( } 2 \text { yrs }): 35 \% \\
\text { 2. OS ( } 2 \text { yrs): } 31 \% \\
\text { DSS ( } 2 \text { yrs): } 42 \% \\
\text { LC (2 yrs): } 65 \%\end{array}$ & $\mathrm{LC}-p=0.094$ \\
\hline $\begin{array}{l}\text { Veeze-Kuijpers } \\
\text { et al. [37] }\end{array}$ & 42 & $\begin{array}{l}30 \text { Gy (15 frac- } \\
\text { tions at } 2 \text { Gy), } \\
\text { since } 1985- \\
40 \text { Gy in } 16 \text { frac- } \\
\text { tions at } 2.5 \text { Gy }\end{array}$ & $\begin{array}{l}\text { 192/r wire, } \\
15 \text { Gy/75 hours, } \\
2 \text { sessions } \\
\text { (schedules } \\
\text { changed for } \\
\text { some patients) }\end{array}$ & $\begin{array}{l}\text { Dose prescribed } \\
\text { at } 10 \mathrm{~mm}\end{array}$ & $\begin{array}{l}\text { MS: } 10 \text { months } \\
15 \% \text { of patients } \geq 2 \text { yrs }\end{array}$ & n.d. \\
\hline $\begin{array}{l}\text { Gonzalez Gonza- } \\
\text { lez et al. [38] }\end{array}$ & $\begin{array}{l}\text { 1. Group I-41 } \\
\text { (+ surgery), } \\
\text { Group II-19 } \\
\text { (unresectable) }\end{array}$ & $\begin{array}{l}\text { 1. } 45 \mathrm{~Gy} \\
\text { (median) } \\
2.48 \mathrm{~Gy} \\
\text { (median) }\end{array}$ & $\begin{array}{l}\text { 192Ir wire } \\
\text { 1. } 10 \mathrm{~Gy} \\
\text { 2. } 22-25 \mathrm{~Gy}\end{array}$ & $\begin{array}{l}\text { BT - dose pre- } \\
\text { scribed at } 10 \mathrm{~mm}\end{array}$ & $\begin{array}{l}\text { 1. MS: } 24 \text { months } \\
\text { 2. MS: } 10.4 \text { months }\end{array}$ & n.d. \\
\hline $\begin{array}{l}\text { Eschelmann } \\
\text { et al. [39] }\end{array}$ & 11 & $\begin{array}{l}\text { 25-56 Gy, frac- } \\
\text { tions 1.8-2.0 Gy }\end{array}$ & $\begin{array}{c}192 \text { Ir wire } \\
25 \text { Gy (mean } \\
\text { dose), 15-31 Gy }\end{array}$ & $\begin{array}{l}\text { BT - dose pre- } \\
\text { scribed at } 10 \mathrm{~mm}\end{array}$ & MS: 22.6 months & n.d. \\
\hline $\begin{array}{l}\text { Takamura et al. } \\
\text { [40] }\end{array}$ & 93 & $\begin{array}{l}50 \text { Gy, } 25 \text { frac- } \\
\text { tions at } 2 \text { Gy }\end{array}$ & $\begin{array}{c}\text { 192Ir wire } \\
\text { 27-50 Gy } \\
\text { (median 39.2) }\end{array}$ & $\begin{array}{l}\text { BT - dose pre- } \\
\text { scribed at } 5 \mathrm{~mm}\end{array}$ & $\begin{array}{l}\text { MS: } 2 \text { yrs: } 15 \text { months } \\
5 \text { yrs: } 4 \text { months }\end{array}$ & n.d. \\
\hline Shin et al. [41] & $\begin{array}{l}1.17 \\
2.14\end{array}$ & $\begin{array}{c}\text { 36-55 Gy } \\
\text { (median 50.4) }\end{array}$ & $\begin{array}{c}\text { 1. No BT } \\
\text { 2. } 3 \times 5 \text { Gy HDR }\end{array}$ & $\begin{array}{c}\text { BT - dose pre- } \\
\text { scribed at } 1.5 \mathrm{~mm}\end{array}$ & $\begin{array}{l}\text { 1. RR: } 53 \% \\
\text { 2. RR: } 36 \% \\
\text { 1. OS }(2 \mathrm{y}): 0 \% \\
\text { 2. OS }(2 \mathrm{y}): 21 \%\end{array}$ & $\begin{array}{l}\mathrm{RR}-p>0.05 \\
\mathrm{OS}-p=0.015\end{array}$ \\
\hline $\begin{array}{l}\text { Schleicher et al. } \\
\text { [42] }\end{array}$ & $\begin{array}{l}1.18 \\
2.12\end{array}$ & $\begin{array}{c}\text { Median: } 30 \text { Gy, } \\
19 \text { fractions at } \\
1.6 \text { Gy }\end{array}$ & $\begin{array}{l}\text { 1. No BT } \\
\text { 2. median } 40 \text { Gy, } \\
\text { 4-5 fractions, } \\
\text { HDR }\end{array}$ & $\begin{array}{l}\text { BT-dose pre- } \\
\text { scribed at } 5 \mathrm{~mm}\end{array}$ & $\begin{array}{l}\text { 1. OS: } 3.9 \text { months } \\
\text { 2. OS: } 9.1 \text { months }\end{array}$ & OS $-p<0.05$ \\
\hline $\begin{array}{l}\text { Kamada et al. } \\
{[43]}\end{array}$ & $\begin{array}{l}1.42 \\
2.103\end{array}$ & $\begin{array}{c}\text { Median 40-50 Gy, } \\
\text { fractions at } \\
2.0-2.5 \text { Gy }\end{array}$ & $\begin{array}{l}\text { 192 Ir wire } \\
\text { 1. No BT } \\
\text { 2. } 25 \text { Gy }\end{array}$ & $\begin{array}{l}\text { BT-dose pre- } \\
\text { scribed at } 5 \mathrm{~mm}\end{array}$ & $\begin{array}{l}\text { 1. MS: } 4.3 \text { months } \\
\text { 2. MS: } 9.3 \text { months }\end{array}$ & n.d. \\
\hline $\begin{array}{l}\text { Ghafoori et al. } \\
{[44]}\end{array}$ & $\begin{array}{l}1.8 \\
2.23\end{array}$ & $\begin{array}{l}\text { 30-62 Gy, } \\
\text { median - } 45 \text { Gy, } \\
\text { fractions } 1.8 \text { to } \\
3 \text { Gy }\end{array}$ & $\begin{array}{c}\text { 192Ir wire } \\
\text { 1. Yes } \\
\text { (median } 25 \text { Gy) } \\
\text { 2. No BT }\end{array}$ & $\begin{array}{l}\text { BT - dose pre- } \\
\text { scribed at 5-10 } \\
\mathrm{mm}\end{array}$ & $\begin{array}{l}\text { 1. MS ( } 2 \text { yrs): } 22 \\
\text { months } \\
\text { (5 yrs) - } 13 \text { months } \\
\text { 2. MS ( } 5 \text { yrs): } 5 \\
\text { months }\end{array}$ & $p=0.096$ \\
\hline
\end{tabular}

EBRT - external beam radiotherapy, BT - brachytherapy, MS - median survival, yrs - years, n.d. - no data, HDR - high-dose-rate, OS - overall survival, DSS - disease specific survival, $L C$ - local control, $R R$ - recurrence rate 
ary tract, which may be associated with better quality of life (QoL) and OS. Well-designed prospective trials should address the efficacy of brachytherapy.

2. Brachytherapy can be used as a palliative treatment to facilitate the outflow of bile. For unresectable patients, the goal of treatment is thus prevention of locoregional disease progression to enhance survival and quality of life.

3. Brachytherapy can be applied as radical treatment: alone in small inoperable tumors or in combination with EBRT/chemotherapy in advanced disease for unresectable patients.

4. Brachytherapy as adjuvant treatment alone after subradical excision may be combined with EBRT.

\section{Acknowledgements}

Some data presented in this manuscript were published in our previous publications cited in the text.

\section{Disclosure}

Authors report no conflict of interest.

\section{References}

1. Yoshioka Y, Ogawa K, Oikawa H et al. Factors influencing survival outcome for radiotherapy for biliary tract cancer: a multicenter retrospective study. Radiother Oncol 2014; 10: 546-552.

2. Skowronek J, Sowier A, Skrzywanek P. Intraluminal Pulsed Dose Rate (PDR) brachytherapy and trans-hepatic technique in treatment of locally advanced bile duct cancer - preliminary assessment. Rep Pract Radioth Oncol 2007; 2: 125-133.

3. Siegel RL, Miller KD, Jemal A. Cancer Statistics, 2015. Ca Cancer J Clin 2015; 65: 5-29.

4. Cheng SH, Huang AT. Liver and Hepatobiliary Tract - Chapter 57. In: Perez and Brady's Principles and Practice of Radiation Oncology. $5^{\text {th }}$ ed. Halperin EC, Perez CA, Brady LW (eds.). Lippincott Williams \& Wilkins, Philadelphia 2008.

5. Williams TM, Majithia L, Wang SJ et al. Defining the role of adjuvant therapy: cholangiocarcinoma and gall bladder cancer. Semin Radiat Oncol 2014; 24: 94-104.

6. Baer HU, Stain SC, Dennison AR et al. Improvements in survival by aggressive resections of hilar cholangiocarcinoma. Ann Surg 1993; 217: 20-27.

7. Buskirk SJ, Gunderson LL, Adson MA et al. Analysis of failure following curative irradiation of gallbladder and extrahepatic bile duct carcinoma. Int J Radiat Oncol Biol Phys 1984; 10: 2013-2023.

8. Cameron JL, Pitt HA, Zinner MJ et al. Management of proximal cholangiocarcinomas by surgical resection and radiotherapy. Am J Surg 1990; 159: 91-97.

9. Skowronek J, Sowier A, Skrzywanek P. Trans-hepatic technique and intraluminal Pulsed Dose Rate (PDR-BT) brachytherapy in treatment of locally advanced bile duct and pancreas cancer. J Contemp Brachytherapy 2009; 1: 97-104.

10. Jabbour SK, Mulvihill D. Defining the Role of Adjuvant Therapy: Ampullary and Duodenal Adenocarcinoma. Semin Radiat Oncol 2014; 24: 85-93.

11. Fields JN, Emami B. Carcinoma of the extrahepatic biliary system - results of primary and adjuvant radiotherapy. Int J Radiat Oncol Biol Phys 1987; 13: 331-338.

12. Montemaggi P, Costamagna G, Dobelbower RR et al. Intraluminal brachytherapy in the treatment of pancreas and bile duct carcinoma. Int J Radiat Oncol Biol Phys 1995; 32: 437-443.
13. Veeze-Kuijpers B, Meerwaldt JH, Lameris JS et al. The role of radiotherapy in the treatment of bile duct carcinoma. Int J Radiat Oncol Biol Phys 1990; 18: 63-67.

14. Hadjis NS, Blenkharn JI, Alexander N et al. Outcome of radical surgery in hilar cholangiocarcinoma. Surgery 1990; 107: 597-604.

15. Nagorney DM, Donohue JH, Faruell MB et al. Outcomes after curative resections of cholangiocarcinoma. Arch Surg 1993; 128: 871-879.

16. Chung C, Bautista N, O'Connell TX. Prognosis and treatment of bile duct carcinoma. Am Surg 1998; 64: 921-925.

17. Adam A, Chetty N, Roddie M et al. Self-expandable stainless steel endoprostheses for treatment of malignant bile duct obstruction. Am J Radiol 1991; 156: 321-325.

18. Minsky BD, Kemeny N, Armstrong JG et al. Extrahepatic biliary system cancer: an update of a combined modality approach. Am J Clin Oncol 1991; 14: 433-437.

19. Moerman CJ, Bueno-de-Mesquita HB. The epidemiology of gallbladder cancer: lifestyle related risk factors and limited surgical possibilities for prevention. Hepatogastroenterology 1999; 46: 1533-1539.

20. Morganti AG, Trodella L, Valentini V et al. Combined modality treatment in unresectable extrahepatic biliary carcinoma. Int J Radiat Oncol Biol Phys 2000; 46: 913-919.

21. Foo ML, Gunderson LL, Bender CE et al. External Radiation Therapy and Transcatheter Iridium in The Treatment Of Extrahepatic Bile Duct Carcinoma. Int J Radiat Oncol Biol Phys 1997; 39: 929-933.

22. Fritz E, Brambs H-J, Schraube E et al. Combined external beam radiotherapy and intraluminal high dose rate brachytherapy on bile duct carcinomas. Int J Radiat Oncol Biol Phys 1994; 29: 855-861.

23. Johnson DW, Safai C, Goffinet DR. Malignant obstructive jaundice: treatment with external-beam and intracavitary radiotherapy. Int J Radiat Oncol Biol Phys 1985; 11: 411-416.

24. Fogel TD, Weissberg JB. The role of radiation therapy in carcinoma of the extrahepatic bile ducts. Int J Radiat Oncol Biol Phys 1984; 10: 2251-2258.

25. Gonzfilez DG, Gerard JR, Maners AW et al. Results of radiation therapy in carcinoma of the proximal bile duct (Klatskin tumor). Sere Liver Dis 1990; 10: 131-141.

26. Montemaggi P, Morganti AG, Dobelbower Jr RR et al. Role of intraluminal brachytherapy in extrahepatic bile duct and pancreatic cancers: is it just for palliation? Radiology 1996; 199: 861-866

27. Dobelbowe, RR, Montemaggi P. Brachytherapy for pancreatic cancer: a review. Hepatogastroenterology 1996; 43: 333-337.

28. Fritz P, Brambs HJ, Schraube P et al. Combined external beam radiotherapy in intraluminal high dose rate brachytherapy on bile duct carcinoma. Int J Radiat Oncol Biol Phys 1994; 29: 855-861.

29. Shinohara ET, Guo M, Mitra N et al. Brachytherapy in the treatment of cholangiocarcinoma. Int J Radiat Oncol Biol Phys 2010; 78: 722-728.

30. Lu JJ, Bains YS, Abdel-Wahab M et al. High-dose-rate remote afterloading intracavitary brachytherapy for the treatment of extra hepatic biliary duct carcinoma. Cancer 2002; 8: 74-78.

31. Chen Y, Wang X-L, Yan Z-P et al. HDR-192Ir intraluminal brachytherapy in treatment of malignant obstructive jaundice. World J Gastroenterol 2004; 10: 3506-3510.

32. Yoshioka Y, Ogawa K, Oikawa H et al. Impact of intraluminal brachytherapy on survival outcome for radiation therapy for unresectable biliary tract cancer: a propensity-score matched-pair analysis. Int J Radiation Oncol Biol Phys 2014; 89: 822-829.

33. Yamaguchi K, Chijiiwa K, Saiki S et al. Carcinoma of the extrahepatic bile duct: mode of spread and its prognostic implications. Hepatogastroenterology 1997; 44: 1256-1261. 
34. Nori D, Parikh S, Sundararaman S et al. Brachytherapy in the treatment of pancreas and bile duct cancer. In: Principles and Practice of Brachytherapy: Using Afterloading Systems. Joslin CA, Flynn A, Hall EJ (eds.). Arnold, New York 2001; 325-332.

35. Yoshida T, Aramaki M, Bandoh T et al. Para-aortic lymph node metastasis in carcinoma of the distal bile duct. Hepatogastroenterology 1998; 45: 2388-2391.

36. Alden ME, Mohiuddin M. The impact of radiation dose in combined external beam and intraluminal Ir-192 brachytherapy for bile duct cancer. Int J Radiat Oncol Biol Phys 1994; 28: 945-951.

37. Veeze-Kuijpers B, Meerwaldt JH, Lameris JS et al. The role of radiotherapy in the treatment of bile duct carcinoma. Int $J$ Radiat Oncol Biol Phys 1990; 18: 63-67.

38. Gonzalez Gonzalez D, Gouma D, Rauws E et al. Role of radiotherapy, in particular intraluminal brachytherapy, in the treatment of proximal bile duct carcinoma. Ann Oncol 1999; 10: 215-220.

39. Eschelman D, Shapiro M, Bonn J et al. Malignant biliary duct obstruction: long-term experience with Gianturco stents and combined-modality radiation therapy. Radiology 1996; 200: 717-724.

40. Takamura A, Saito H, Kamada $\mathrm{T}$ et al. Intraluminal lowdose-rate 192Ir brachytherapy combined with external beam radiotherapy and biliary stenting for unresectable extrahepatic bile duct carcinoma. Int J Radiat Oncol Biol Phys 2003; 57: 1357-1365.

41. Shin HS, Seong J, Kim WC et al. Combination of external beam irradiation and high-dose-rate intraluminal brachytherapy for inoperable carcinoma of the extrahepatic bile ducts. Int J Radiat Oncol Biol Phys 2003; 57: 105-112.

42. Schleicher UM, Staatz G, Alzen G et al. Combined external beam and intraluminal radiotherapy for irresectable Klatskin tumors. Strahlenther Onkol 2002; 178: 682-687.

43. Kamada T, Saitou H, Takamura A et al. The role of radiotherapy in the management of extrahepatic bile duct cancer: an analysis of 145 consecutive patients treated with intraluminal and/or external beam radiotherapy. Int J Radiat Oncol Biol Phys 1996; 34: 767-774.

44. Ghafoori AP, Nelson JW, Willett CG et al. Radiotherapy in the treatment of patients with unresectable extrahepatic cholangiocarcinoma. Int J Radiat Oncol Biol Phys 2011; 81: 654-659. 